\title{
Impaired Diurnal Adrenal Rhythmicity Restored by Constant Infusion of Corticotropin-releasing Hormone in Corticotropin-releasing Hormone-deficient Mice
}

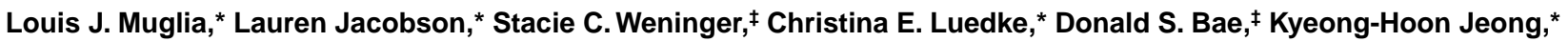 \\ and Joseph A. Majzoub* \\ *Division of Endocrinology, Children’s Hospital, and ${ }^{\ddagger}$ Howard Hughes Medical Institute, Boston, Massachusetts 02115
}

\begin{abstract}
The normal pattern of daily glucocorticoid production in mammals requires circadian modulation of hypothalamicpituitary-adrenal axis activity. To assess both the factors responsible for imparting this diurnal profile and its physiologic importance, we have exploited corticotropin-releasing hormone ( $\mathrm{CRH})$-deficient mice generated by homologous recombination in embryonic stem cells. CRH-deficient mice have lost normal circadian variations in plasma ACTH and glucocorticoid while maintaining normal circadian locomotor activity. Constant peripheral infusion of CRH produced marked diurnal excursions of plasma glucocorticoid, indicating that CRH acts in part as a permissive factor for other circadian modulators of adrenocortical activity. The presence of atrophic adrenals in CRH-deficient mice without an overt deficit in basal plasma ACTH concentration suggests that the diurnal increase in ACTH is essential to maintain normal adrenal function. (J. Clin. Invest. 1997. 99:2923-2929.) Key words: corticotropin-releasing hormone - knockout mice $\bullet$ circadian rhythm $\cdot$ adrenal $\cdot$ glucocorticoids
\end{abstract}

\section{Introduction}

Circadian variation in metabolism and behavior is a conserved pattern of biological rhythmicity common to the majority of eukaryotic and some prokaryotic species $(1,2)$. Among circadian rhythms in higher mammals, one of the most robust diurnal patterns occurs in modulation of the hypothalamic-pituitary-adrenal (HPA) ${ }^{1}$ axis. In humans and rodents, peak adrenal glucocorticoid production occurs just before the active period. This corresponds to the light phase of a light/dark (LD) cycle for humans, and the dark phase of the LD cycle for

Address correspondence to Joseph A. Majzoub, Division of Endocrinology, Children's Hospital, 300 Longwood Avenue, Boston, MA 02115. Phone: 617-355-6421; FAX: 617-730-0741; E-mail: majzoub@ a1.tch.harvard.edu The present address for Louis J. Muglia is Washington University School of Medicine, St. Louis Children's Hospital, One Children's Place, St. Louis, MO 63110.

Received for publication 28 January 1997 and accepted in revised form 26 March 1997.

1. Abbreviations used in this paper: $\mathrm{CRH}$, corticotropin-releasing hormone; HPA, hypothalamic-pituitary adrenal; KO, knockout; LD, light/dark (cycle); SCN, suprachiasmatic nucleus; WT, wild type.

J. Clin. Invest.

(C) The American Society for Clinical Investigation, Inc.

0021-9738/97/06/2923/07 \$2.00

Volume 99, Number 12, June 1997, 2923-2929 rats and mice $(3,4)$. Under conditions of constant darkness, circadian rhythms in locomotor behavior and HPA axis function persist, reflecting the function of an endogenous clock mechanism (5-7). This central nervous system pacemaker requires an intact suprachiasmatic nucleus $(\mathrm{SCN})$, since animals with SCN lesions lose rhythmicity of locomotor, adrenocortical, and sleep-wake modulation $(8,9)$.

The neuroendocrine mechanism responsible for generation of the circadian glucocorticoid rhythm has remained incompletely defined. Corticotropin-releasing hormone (CRH; 10), a 41-amino acid peptide synthesized in the paraventricular nucleus of the hypothalamus, has been implicated by immunoneutralization studies in the generation of the circadian peak glucocorticoid levels $(11,12)$. Additionally, hypothalamic CRH mRNA has been shown to rise before the active period and fall before the sleep phase of the rodent LD cycle (13), consistent with the general pattern of glucocorticoid secretion. However, decreases in CRH mRNA expression immediately before the active phase do not correlate with plasma glucocorticoid levels $(13,14)$, suggesting that other factors could contribute to or account for the circadian rhythm in glucocorticoid secretion. Indeed, high, constant levels of $\mathrm{CRH}$ do not interfere with diurnal variations in glucocorticoid secretion (15). Additionally, direct modulation of glucocorticoid output at the level of the adrenal gland has been implicated by studies using splanchnic nerve transection (16) or assessment of ACTH sensitivity (17), and is further suggested by the relatively small increase in plasma ACTH in comparison to the large increase in plasma glucocorticoid at the circadian peak $(3,18,19)$.

The significance of the circadian pattern of glucocorticoid production has likewise not been definitively established. Normal circadian variation in glucocorticoid production has been associated with modulation of insulin sensitivity and glucose disposal in humans, with cortisol and insulin secretion varying inversely (20-22). In rodents, corticosterone has been found to affect carbohydrate appetite, such that higher corticosterone levels at the onset of feeding result in a preference for carbohydrates $(23,24)$. Conversely, dysregulated circadian modulation of the HPA axis is often associated with disease. Major depressive illness, for example, is characterized by elevated glucocorticoid levels during the diurnal nadir of adrenocortical activity $(25,26)$, which are associated with elevations in cerebrospinal fluid CRH concentrations (27). This may have prognostic relevance, since those patients with increased cortisol production exhibit a less favorable response to some types of therapy (28).

To assess the need for $\mathrm{CRH}$ in the establishment of normal diurnal corticosterone production and to determine the physiologic manifestations of impaired diurnal glucocorticoid production, we report here our findings in CRH-deficient (knockout $[\mathrm{KO}])$ mice generated by homologous recombination in embryonic stem cells $(29,30)$. 


\section{Methods}

Animal housing and circadian plasma sampling. Wild-type (WT) and CRH KO mice were maintained under 14:10 h LD cycles, and were fed ad libitum unless otherwise indicated. The mice that were used for all studies were greater than $8 \mathrm{wk}$ of age and of a C57BL/6 $\times 129$ Sv genetic background maintained by breeding within our population. All mouse protocols were in accordance with National Institutes of Health guidelines, and were approved by the Animal Care and Use Committee of Children's Hospital in Boston. Plasma for measurement of corticosterone, ACTH, and blood glucose was obtained by rapid retroorbital phlebotomy into heparinized capillary tubes with a total time from first handling the animal to completion of bleeding not exceeding $30 \mathrm{~s}$. For the 24-h sampling cycle depicted in Fig. 1, $c$ and $d$, the time points were distributed across several days, with a recovery period of several days for each mouse, so that no mouse was bled more than once on a given day. Blood was collected on ice, and plasma was separated by centrifugation and stored at $-80^{\circ} \mathrm{C}$ until assay. Plasma concentrations of corticosterone (ICN Biomedicals, Inc., Costa Mesa, CA) and ACTH (Incstar Corp., Stillwater, MN) were determined by RIA as described previously (31), and plasma glucose was determined by the glucose oxidase method in an APEC automated glucose analyzer (Danvers, MA). Statistical analysis was by ANOVA or paired $t$ test.

Food restriction. The restricted feeding regimen entailed limitation of food access to 0930 and $1130 \mathrm{~h}$ with lights on at 0700 and off at $1900 \mathrm{~h}$ (32). Plasma samples were obtained at 0900 and $0630 \mathrm{~h}$ for demonstration of circadian phase reversal in $n=5-7$ WT or CRH KO females, and $n=6 \mathrm{WT}$ or CRH KO control ad libitum fed mice.

Cortrosyn stimulation testing. Synthetic ACTH 1-24 (Cortrosyn) stimulation testing was performed $1-2 \mathrm{~h}$ after lights on in ad libitumfed mice. Groups of $n=5 \mathrm{WT}$ or CRH KO female mice were bled by retroorbital phlebotomy 60 min after either $(a)$ no injection, $(b)$ intraperitoneal injection of $10 \mu \mathrm{g} / \mathrm{kg}$ Cortrosyn, or $(c)$ intraperitioneal injection of vehicle (Hepes-buffered saline with $0.3 \%$ BSA). Plasma corticosterone was measured by RIA as described above.

Adrenalectomy for evaluation of diurnal ACTH variation. Groups of four adult CRH KO or WT male mice underwent adrenalectomy via flank incision under aseptic conditions using tribromoethanol anesthesia. $4 \mathrm{wk}$ after adrenalectomy, mice were subjected to retroorbital phlebotomy at $2 \mathrm{~h}$ before lights off, followed $2 \mathrm{~d}$ later by repeat phlebotomy $1 \mathrm{~h}$ after lights on. Adequacy of adrenalectomy was confirmed by corticosterone RIA and elevated plasma ACTH concentrations.

Effect of constant CRH infusion on circadian adrenal function. Constant infusion of CRH was performed as described (33). Groups of $n=5-6$ adult CRH KO female mice maintained on a 12:12 LD cycle (lights on at 0700, lights out at 1900) underwent subcutaneous osmotic minipump placement (ALZA Corp., Palo Alto, CA) and received infusion of either vehicle alone ( $1 \%$ acetic acid, $1 \mathrm{mg} / \mathrm{ml}$ ascorbate, and $10 \mathrm{mg} / \mathrm{ml} \mathrm{BSA}$ ) or daily doses of $0.1,0.25,0.5$, or $1 \mu \mathrm{g} / \mathrm{d}$ of $\mathrm{CRH}$ in vehicle. $2 \mathrm{~d}$ after pump placement, mice underwent initial plasma sampling 1-2 $\mathrm{h}$ after lights on, followed by repeat sampling at $1830 \mathrm{~h}$ ( $30 \mathrm{~min}$ before lights out) the next day. An additional set of circadian nadir and peak samples was obtained at the same times of day on days 5 and 6 after pump implantation, respectively. Plasma corticosterone and ACTH were measured by RIA in all samples, with values subjected to statistical analysis by ANOVA and paired or nonpaired $t$ tests, as appropriate.

Plasma insulin measurement. Plasma insulin was measured by RIA kit using half the volumes specified by the manufacturer (Linco, St. Charles, MO) in $n=4-6$ CRH KO or WT mice $1 \mathrm{~h}$ after lights on. Volume reduction for the reactions did not impair the performance of the assay. Plasma insulin values were analyzed for statistical significance by single-factor ANOVA.

Assessment of circadian locomotor activity. Groups of $n=5 \mathrm{CRH}$ $\mathrm{KO}$ and WT male mice were individually housed within light-controlled isolation chambers in cages containing monitored activity wheels, and they were allowed ad libitum access to food. All animals were entrained to an initial 14:10 LD cycle with lights off at $2100 \mathrm{~h}$ and lights on at $0700 \mathrm{~h}$. After $\sim 3 \mathrm{wk}$ of activity recording on this cycle, a phase shift of $6 \mathrm{~h}$ was introduced by advancing lights off to $1500 \mathrm{~h}$ and lights on to $0100 \mathrm{~h}$. After $2 \mathrm{wk}$ on the new light cycle, the mice were placed in constant darkness (dim red light) for $10 \mathrm{~d}$ for assessment of endogenous period, and were then returned to the original LD cycle. The endogenous period was determined by measuring the interval between the onset of successive active phases, and the duration of activity was determined by measuring the time of sustained wheel running during the active period.

\section{Results}

Impaired diurnal adrenal rhythmicity with CRH deficiency. To determine the effect of loss of $\mathrm{CRH}$ on diurnal adrenal modulation, we compared the plasma glucocorticoid profile of WT and CRH KO mice. Analysis of plasma corticosterone levels at circadian nadir (a.m., $2 \mathrm{~h}$ after lights on) and circadian peak (p.m., $1 \mathrm{~h}$ before lights out) revealed a 9-20 $\mu \mathrm{g} / \mathrm{dl}$ increase in corticosterone level in WT male and female mice at the onset of the dark period (Fig. 1, $a$ and $b$ ). In CRH KO male mice, the average serum corticosterone concentration was below the limit of assay sensitivity in both the a.m. and p.m. hours $(<1.0 \mu \mathrm{g} / \mathrm{dl})$. For female $\mathrm{KO}$ mice, the circadian variation in serum corticosterone was most often absent (e.g., a.m. $2.1 \pm 0.7$ vs. p.m. $2.0 \pm 0.5 \mu \mathrm{g} / \mathrm{dl}$, Fig. $1 a$ ), though occasional experiments using paired samples in the same mice showed very low amplitude differences of statistical significance between the a.m. and p.m. (a.m. $0.9 \pm 0.4$ vs. p.m. $2.1 \pm 0.7 \mu \mathrm{g} /$ dl, Fig. $1 b$ ). To ensure that taking a single a.m. and p.m. blood sample had not missed diurnal increases of greater magnitude at another time, we performed plasma sampling over a 24-h period at 2-h intervals in WT and $\mathrm{KO}$ female mice. The female $\mathrm{KO}$ mice had a flat plasma glucocorticoid profile over the entire cycle, whereas the WT mice displayed the anticipated diurnal variation (Fig. 1c).

Food restriction to the light phase of the LD cycle shifts the adrenal corticosterone peak in WT rodents from anticipation of darkness to anticipation of feeding, and induces HPA diurnal variation in otherwise arrhythmic animals with SCN lesions $(32,34)$. Next, we sought to determine if food restriction could similarly induce HPA diurnal variation in CRH KO mice. Restriction of feeding to a 2-h period of the light phase failed to induce a corticosterone rise in female CRH KO mice before

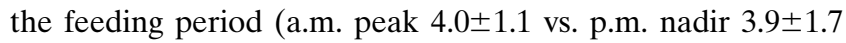
$\mu \mathrm{g} / \mathrm{dl}, P=0.97)$, while WT mice demonstrated the anticipated phase reversal in the diurnal profile (a.m. peak $39.4 \pm 7.2$ vs. p.m. nadir $14.6 \pm 5.1 \mu \mathrm{g} / \mathrm{dl}, P<0.03)$.

To assess whether impaired adrenal secretory capacity in CRH KO mice had masked our ability to detect a circadian variation in HPA axis activity, we stimulated adrenal corticosterone production in WT and KO female mice with exogenous ACTH. The KO female mice demonstrated an adrenal response to ACTH that was $\sim 35 \%$ of that of $\mathrm{WT}$, with some animals attaining plasma levels as high as $20 \mu \mathrm{g} / \mathrm{dl}$ (Fig. $2 a$ ).

Impaired ACTH secretion with CRH deficiency. To determine whether $\mathrm{CRH}$-deficient mice had circadian variation in ACTH production, plasma samples were obtained at circadian nadir and peak in intact and adrenalectomized WT and KO mice. In WT mice with intact adrenals, no elevation in plasma ACTH production was found (a.m. $174 \pm 24 \mathrm{pg} / \mathrm{ml}$ vs. p.m. $146 \pm 13 \mathrm{pg} / \mathrm{ml}, P=0.3$ ). Adrenalectomy allowed the demon- 
a

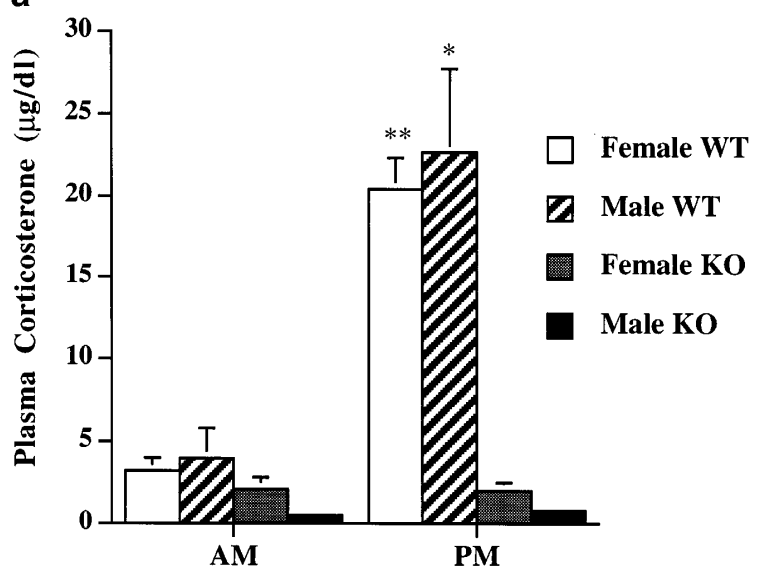

b

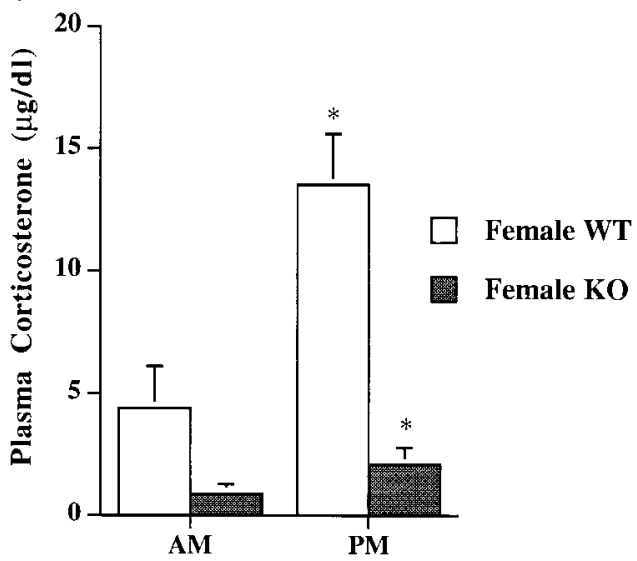

C

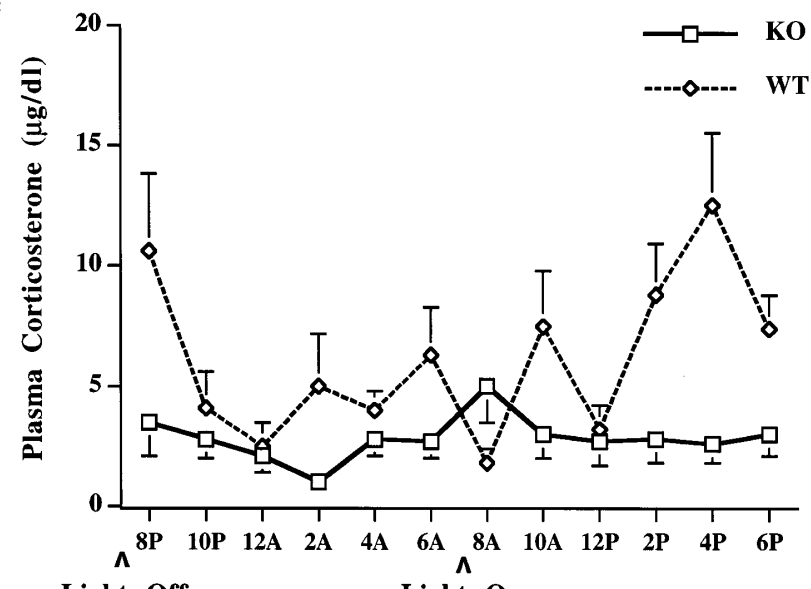

d

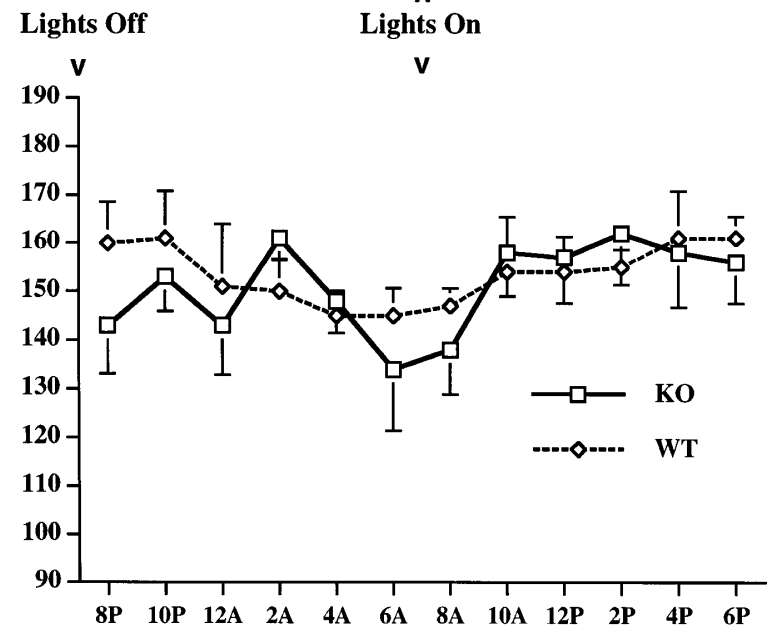

Figure 1. Circadian analysis of plasma corticosterone and glucose in KO and WT mice. (a) Plasma corticosterone measurement in male and female WT and KO mice at circadian nadir (a.m., $2 \mathrm{~h}$ after lights on) and circadian peak (p.m., $1 \mathrm{~h}$ before lights off) on a 14:10 LD cycle (*P<0.05, ** $P<0.01)$. (b) Occasionally, diurnal sampling revealed a very low amplitude increase in the plasma corticosterone of female KO mice of statistical significance $(* P<0.05)$, as demonstrated here. (c) Measurement of plasma corticosterone every $2 \mathrm{~h}$ over a 24 -h cycle in female KO (solid line) and WT (dashed line) mice on a 12:12 LD cycle ( $n=5$ per genotype per time point). (d) Measurement of plasma glucose in ad libitum-fed mice every 2 h over a 24 -h cycle ( $n=5$ per genotype per time point).

stration of an $\sim$ twofold elevation in p.m. compared to a.m. plasma ACTH in WT male mice (a.m. 1,423 \pm 332 vs. p.m. $2,764 \pm 648 \mathrm{pg} / \mathrm{ml}$ ), as has been shown by others (18). In intact CRH KO mice, although plasma corticosterone remained low, plasma ACTH did not increase above basal a.m. values (a.m. $158 \pm 11$ vs. p.m. $157 \pm 11 \mathrm{pg} / \mathrm{ml}, n=5-6)$. Furthermore, after adrenalectomy, there was still no p.m. increase in plasma ACTH in KO mice (a.m. $227 \pm 24$ vs. p.m. $226 \pm 21$ pg/ml; Fig. $2 b$ ).

Constant infusion of CRH restores a diurnal adrenal secretory pattern. CRH could augment circadian ACTH and glucocorticoid secretion by varying in a circadian fashion and/or by maintaining corticotroph and, indirectly, adrenocortical responsivenes to other pulsatile secretagogues. The latter possibility is suggested by our observation of occasional low magnitude diurnal plasma corticosterone elevations in the female $\mathrm{KO}$ mice. To determine whether tonic CRH replacement could result in circadian adrenocortical rhythmicity, female $\mathrm{CRH}$ $\mathrm{KO}$ mice received chronic peripheral administration of $\mathrm{CRH}$ via osmotic minipumps at doses ranging from 0.1 to $1.0 \mu \mathrm{g} / \mathrm{d}$ (33). Constant infusion of $0.25,0.5$, and $1.0 \mu \mathrm{g} / \mathrm{d}$ markedly in- creased circadian peak corticosterone production in $\mathrm{KO}$ mice by $2 \mathrm{~d}$ of treatment, while morning corticosterone levels were also significantly elevated by the two higher doses (Fig. 3). Surprisingly, CRH infusion rates of 0.25 to $1 \mu \mathrm{g} / \mathrm{d}$ restored a robust diurnal rhythm in corticosterone when analyzed 2-6 d after pump placement (Fig. 3). The CRH KO mice infused with vehicle alone exhibited no diurnal variation in plasma ACTH (a.m. $162 \pm 16$ vs. p.m. $174 \pm 9$ pg/ml). Furthermore, CRH infusion did not produce significant a.m./p.m. differences in plasma ACTH at any dose (data not shown).

Intact circadian locomotor behavior in $\mathrm{CRH} \mathrm{KO}$ mice. To determine if CRH KO mice lack other circadian rhythms besides that in pituitary-adrenal function, we analyzed locomotor activity. CRH, outside the paraventricular nucleus of the hypothalamus, is synthesized in many regions of the cerebral cortex and brainstem (35), where it is believed to impart stress-related behaviors $(36,37)$. To assess the role of $\mathrm{CRH}$ in the generation of circadian behavior, wheel running was first monitored under conditions of a fixed LD cycle (14:10 LD). Under these conditions, KO mice exhibited normal wheel running onset and offset, anticipating the dark and light phases of their cy- 

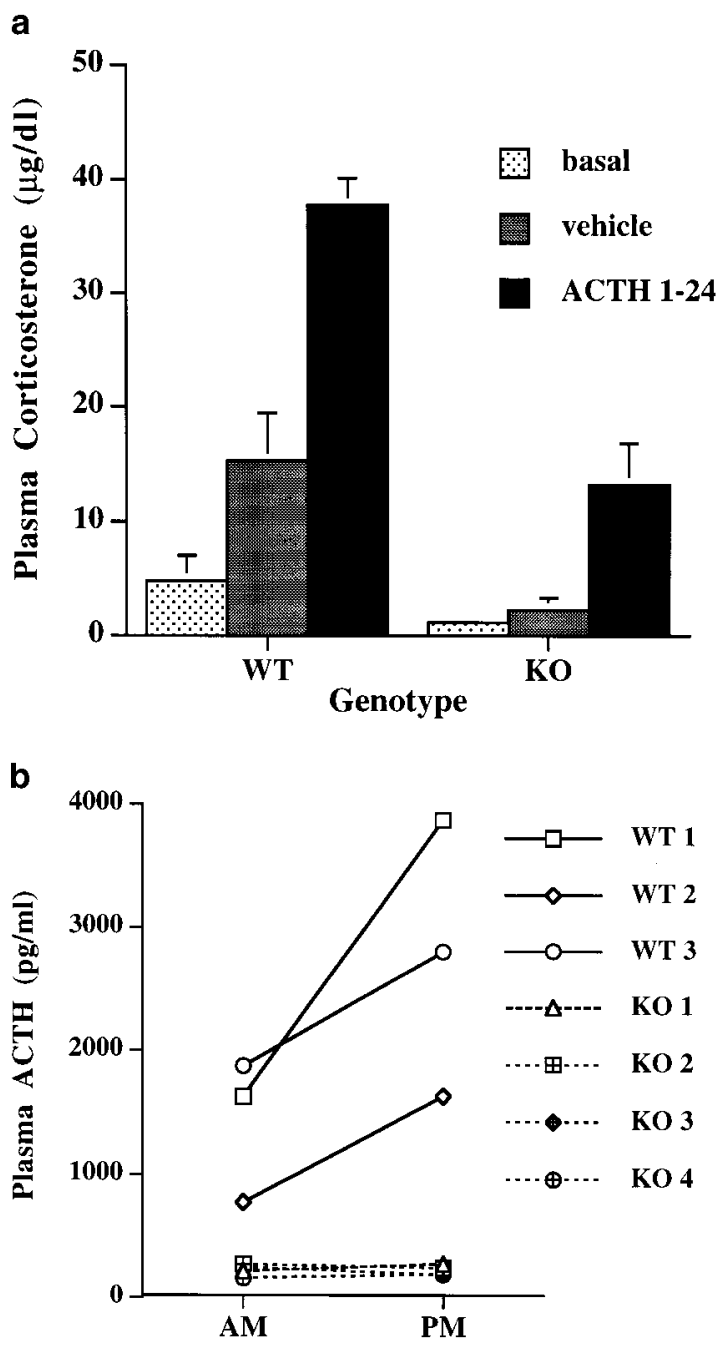

Figure 2. Evaluation of adrenal response to ACTH and circadian modulation of ACTH production. (a) ACTH 1-24 in vehicle or vehicle alone was injected intraperitoneally into female WT and KO mice, followed by retroorbital phlebotomy $60 \mathrm{~min}$ after injection, and compared to basal phlebotomy in unmanipulated mice. KO adrenal glucocorticoid production in response to exogenous ACTH 1-24 was significantly above that in basal $(P<0.01)$ and vehicle-injected $(P<$ $0.05) \mathrm{KO}$ groups. (b) Plasma ACTH determination in adrenalectomized male WT $(n=3)$ and $\mathrm{KO}(n=4)$ mice at circadian nadir (a.m. $1 \mathrm{~h}$ after lights on) and circadian peak (p.m., 1-2 h before lights off).

cles, respectively (Fig. 4). CRH KO mice additionally adapted to a phase shift in light cycle in a fashion similar to WT (Fig. 4), reflecting entrainment to the original LD cycle and gradual reentrainment to the new cycle. Photic cues masking a more subtle defect in endogenous locomotor behavior were evaluated by placing the mice in conditions of constant darkness for several days with continued monitoring of wheel running. Endogenous period ( $\mathrm{KO} 23.3 \pm 0.2 \mathrm{~h}$ vs. WT $23.7 \pm 0.3 \mathrm{~h})$ and duration of activity (KO 7.8 $\pm 2.2 \mathrm{~h}$ vs. WT $7.8 \pm 1.9$ ) did not significantly differ between WT and KO animals. Thus, CRH deficiency impairs circadian adrenocortical activity without significantly affecting locomotor activity.

Effect of impaired diurnal adrenocortical rhythmicity on carbohydrate metabolism. To assess whether a significant al-

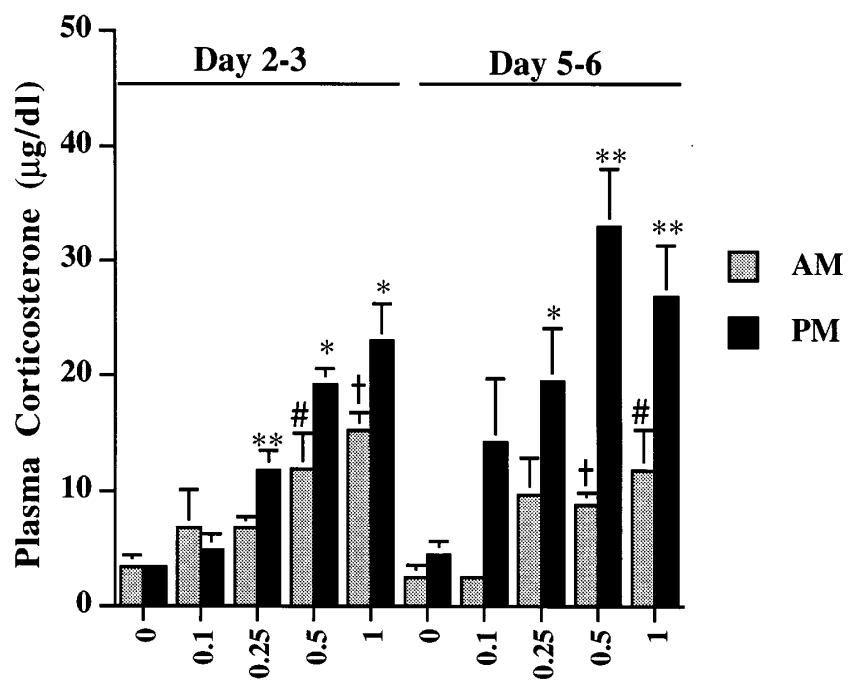

Infused CRH $(\mu \mathrm{g} / \mathrm{d})$

Figure 3. Diurnal pattern of adrenal glucocorticoid production during constant infusion of $\mathrm{CRH}$ in female $\mathrm{KO}$ mice. $\mathrm{CRH}$ was infused subcutaneously via osmotic minipumps at doses of $0-1 \mu \mathrm{g} / \mathrm{d}$. Two sets of a.m.-p.m. plasma samples were obtained on days $2-3$ or days 5-6 after pump implantation, as described in Methods. a.m. and p.m. samples were obtained 1-2 $\mathrm{h}$ after lights on and $30 \mathrm{~min}$ before lights off, respectively, on a 12:12 LD cycle. Significance symbols refer to data from a given sample set, identified at the top of the graph $\left({ }^{*} P<0.05\right.$, ${ }^{* *} P<0.01$ a.m. vs. p.m. for the specified CRH dose; ${ }^{\sharp} P<0.05,{ }^{\dagger} P<$ 0.01 , vs. a.m. levels in vehicle-infused controls). $\square$, a.m.; $\mathbf{\square}$, p.m.

teration in carbohydrate metabolism occurs in CRH KO mice, blood glucose analysis of WT and KO mice was performed over a 24 -h period. No significant difference in the pattern or absolute concentration of blood glucose was demonstrated in the KO mice (Fig. $1 d$ ). However, the plasma insulin level at the circadian nadir tended to be lower in the $\mathrm{KO}$ mice (KO $0.47 \pm 0.13$ vs. WT $1.79 \pm 0.46 \mathrm{ng} / \mathrm{ml}$ ), suggesting increased insulin sensitivity when the nocturnal steroid rise is impaired.

\section{Discussion}

We have used CRH-deficient mice to explore the role of $\mathrm{CRH}$ in the generation of circadian rhythmicity of the pituitary-adrenal axis and locomotor behavior. Our studies demonstrate that $\mathrm{CRH}$ is required for the normal amplitude of the glucocorticoid peak before the active period, but is not required for the generation of a circadian pattern of locomotor activity. Although circadian peak glucocorticoid levels are associated with the active period and CRH has been postulated to affect locomotor behavior during stress, no differences were observed between WT and KO mice in wheel-running activity. Thus, impaired circadian glucocorticoid production in $\mathrm{KO}$ mice is not caused by the loss of normal activity rhythms.

One explanation for our findings could be that the degree of adrenal atrophy exhibited in the context of chronic CRH deficiency prevents detection of circadian adrenal function. While this possibility is not excluded, the ability of CRH KO female mice to generate plasma glucocorticoid concentrations of $12 \mu \mathrm{g} / \mathrm{dl}$ during acute restraint stress (30) and up to $20 \mu \mathrm{g} / \mathrm{dl}$ 

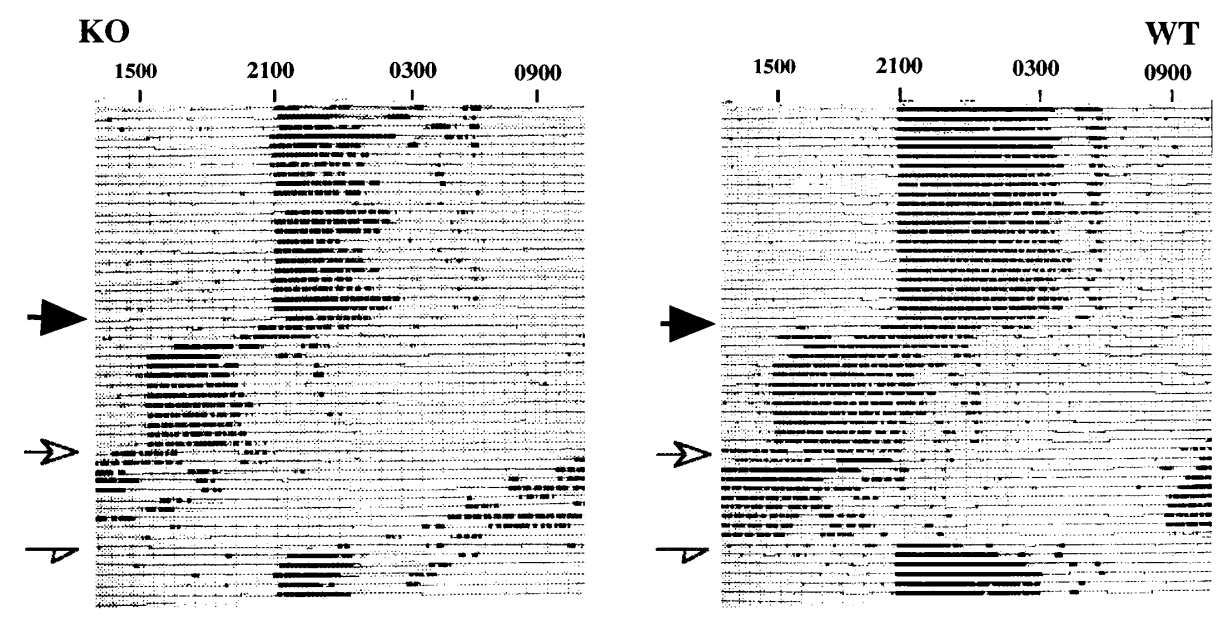

Figure 4. Circadian wheel-running activity. Chart recordings are representative of wheel-running activity in $\mathrm{KO}$ and WT male mice housed in monitored cages within isolation chambers. The initial LD cycle was lights off at $2100 \mathrm{~h}$ and lights on at $0700 \mathrm{~h}$. Each row of the tracing shows one 24-h cycle with the clock time above the panels. Gradual reentrainment to a new LD cycle occured after a phase shift of $6 \mathrm{~h}$ (large thick arrow; lights off at $1500 \mathrm{~h}$, lights on at 0100 ) in both $\mathrm{KO}$ and WT mice. Institution of constant darkness (free-running) resulted in observation of a similar endogenous period of 23.3-23.7 h between genotypes (open arrow), after which the mice reentrained to the original LD cycle (open half arrow).

with Cortrosyn stimulation contrasts with the absence of comparable increases in corticosterone during the more prolonged circadian stimulus for adrenocortical activity (38). These data indicate that there is sufficient adrenal function in CRH KO mice to respond to circadian stimulation, and they argue that $\mathrm{CRH}$ plays an important role in generation of the circadian peak level. The lack of a more prominent circadian increase in corticosterone in female $\mathrm{KO}$ mice also indicates that other factors, such as the recently identified urocortin (39), cannot substitute for $\mathrm{CRH}$ in driving normal circadian peak glucocorticoid secretion or the reentrainment of diurnal glucocorticoid secretion by food restriction.

The ability of CRH-deficient mice to generate a very low amplitude increase in adrenocortical output at circadian peak indicates that $\mathrm{CRH}$ is not the only factor involved in imparting diurnal modulation of the adrenal cortex. This residual low amplitude diurnal variation could reflect altered adrenal secretion caused by direct splanchnic nerve stimulation (16), increased adrenal sensitivity to an unchanged plasma ACTH concentration (17), the reduced ability of other secretagogues to cause ACTH release by the pituitary in the absence of $\mathrm{CRH}$, or altered peripheral clearance of corticosterone with unchanged production. In $\mathrm{CRH} \mathrm{KO}$ mice, the absence of a diurnal variation in plasma ACTH concentration in intact or adrenalectomized animals, along with diurnal rhythmicity in plasma glucocorticoids during constant $\mathrm{CRH}$ infusion, suggest that one component of modulation occurs independently of ACTH rhythmicity. The circadian influence of factors other than $\mathrm{CRH}$ on the adrenal is further demonstrated by the sequelae of constant $\mathrm{CRH}$ infusion in $\mathrm{KO}$ mice. $\mathrm{CRH}$ infusion increased both the absolute circadian peak plasma corticosterone concentration and the relative a.m.-p.m. difference in plasma corticosterone, indicating not only that $\mathrm{CRH}$ can reverse some deficits in female $\mathrm{KO}$ adrenal function, but that $\mathrm{CRH}$ is required to amplify pituitary or adrenocortical responsiveness to other diurnally varying factors. The lack of diurnal variation in plasma $\mathrm{ACTH}$ with constant $\mathrm{CRH}$ infusion does not exclude ACTH stimulation as having a role in the genesis of the diurnal corticosterone rhythm. The augmented corticosterone response to infused $\mathrm{CRH}$ that we observe, together with minimal variations in plasma ACTH concentration, are consistent with the absence of diurnal excursion in ACTH in nonadrenalectomized animals reported in other studies (13, 18). Our evidence for both CRH-dependent and -independent rhythms in adrenocortical activity reconciles previous literature that indicate an absolute requirement for $\mathrm{CRH}$ in peak glucocorticoid secretion with studies that reveal a discordance between the circadian pattern of CRH mRNA expression and plasma glucocorticoids or the maintenance of a diurnal adrenocortical secretory profile in the setting of constant supraphysiologic $\mathrm{CRH}$ infusion (13-15). Because CRH itself varies diurnally, with trough and peak generally consistent with that of adrenocortical activity (13), synchrony of CRH and adrenal rhythms in the WT rodent also probably contribute to the normal circadian profile of glucocorticoid secretion by minimizing nadir and maximizing peak steroid output.

One posited function of the diurnal variation in glucocorticoids is the modulation of carbohydrate metabolism $(40,41)$. Studies in humans have demonstrated relative insulin resistance in the evening with an increased excursion in postmeal plasma glucose in opposite phase to, though dependent on, the morning rise in cortisol $(20,22)$. The physiologic roles of the circadian rhythm in HPA function and glucocorticoid production can be directly assessed in the CRH KO model system without the concomitant loss of mineralocorticoid and adrenomedullary function imparted by adrenalectomy studies. In our rodent studies, we would anticipate the evening rise in glucocorticoid to result in an elevated morning plasma glucose and relative insulin resistance. Consistent with this model, although the 24-h plasma glucose profile was similar between genotypes, the CRH KO mice tend toward a lower a.m. plasma insulin concentration, suggesting less insulin resistance, in the absence of the normal corticosterone rise the previous evening. CRH KO mice do not differ from WT controls in body weight (30), 24-h food intake, or plasma glucagon (our unpublished data). Thus, other determinants of plasma glucose, such as meal timing, other counterregulatory hormones, or glucose transporter expression, may compensate for chronically deficient circadian glucocorticoid production.

In light of this relatively mild effect on carbohydrate metabolism, the greatest impact of insufficient diurnal adrenocortical activation in $\mathrm{KO}$ mice may be the loss of adrenocortical 
function. Aberrant adrenocortical architecture in males and adrenal atrophy in both sexes of KO mice correlates with their inability to mount normal corticosterone responses to stress (30), circadian (Fig. 1, $a-c$ ), and ACTH stimulation (Fig. $2 a$ and our unpublished data). Given these deficits, the similarity in basal plasma immunoreactive ACTH is surprising and suggests that diurnal increases in ACTH above this basal level are necessary to maintain adrenal structure and function. Such increases in ACTH are probably inhibited by elevated glucocorticoid levels at the circadian peak, and are only evident when plasma corticosterone is controlled by adrenalectomy, as we have shown in WT mice and others have shown in rats $(18,42)$. Even partial inhibition of ACTH production by administration of low, constant levels of exogenous corticosterone is associated with reductions in adrenal weight and endogenous corticosterone output (19). In contrast, administration of glucocorticoids on alternate days, even in high doses, spares adrenal atrophy, possibly because circadian ACTH secretion is not suppressed on the intervening day $(43,44)$. Consistent with the hypothesis that circadian modulation of pituitary-adrenal activity is necessary for normal adrenal structure, our preliminary studies indicate that discrepancies in adrenal size and histology between KO and WT mice are much less evident at 2 wk than at 8 wk of age (our unpublished data), corresponding to time points before and after the appearance of circadian rhythmicity at $3 \mathrm{wk}$ of age in the rodent $(45,46)$.

In summary, our findings suggest that the maintenance of normal adrenal structure and function requires $\mathrm{CRH}$ to mediate circadian stimulation of adrenocortical activity. Although $\mathrm{CRH}$ acts at least in part to augment the effects of other circadian modulators of pituitary-adrenal function, diurnal variations in $\mathrm{CRH}$ itself may be essential to confer not only the normal peak, but also the normal nadir of the circadian glucocorticoid rhythm. Normal regulation of CRH may be essential to prevent adrenal atrophy without producing the chronic elevations in glucocorticoids that can cause glucose intolerance, osteoporosis, and muscle wasting (47).

\section{Acknowledgments}

We thank Dr. M. Dallman for advice regarding CRH infusion, Dr. F. Davis for use of circadian monitoring equipment and helpful discussions, M. Yalamas for assistance with experiments, and M. Schaefer and $\mathrm{H}$. Hilderbrand for mouse colony maintenance.

This work was supported by grants from the National Institutes of Health (L.J. Muglia, L. Jacobson, and J.A. Majzoub), Pfizer Pharmaceuticals (L.J. Muglia), National Alliance for Research on Schizophrenia and Depression (L. Jacobson), Howard Hughes Medical Institute Predoctoral Fellowship Program (S.C. Weninger and D.S. Bae), and a Burroughs Wellcome Fund Career Development Award to L.J. Muglia. L.J. Muglia is a Scholar of the Child Health Research Center of Excellence in Developmental Biology at Washington University School of Medicine (HD33688).

\section{References}

1. Kay, S.A., and A.J. Millar. 1995. New models in vogue for circadian clocks. Cell. 83:361-364.

2. Hastings, M. 1996. Circadian rhythms: peering into the molecular clockwork. J. Neuroendocrinol. 7:331-340.

3. Dallman, M.F., W.C. Engeland, J.C. Rose, C.W. Wilkinson, J. Shinsako, and F. Siedenburg. 1978. Nycthemeral rhythm in adrenal responsiveness to ACTH. Am. J. Physiol. 235:R210-R218.

4. Krieger, D.T. 1975. Circadian pituitary adrenal rhythms. Adv. Exp. Med. Biol. 54:169-189.
5. Szafarczyk, A., G. Ixart, F. Malaval, J. Nouguier-Soule, and I. Assenmacher. 1979. Effects of lesions of the suprachiasmatic nuclei and p-chlorophenylalanine on the circadian rhythms of adrenocorticotropic hormone and corticosterone in the plasma, and on locomotor activity of rats. J. Endocrinol. 83:1-16.

6. Schwartz, W.J., and P. Zimmerman. 1990. Circadian timekeeping in BALB/c and C57BL/6 inbred mouse strains. J. Neurosci. 10:3685-3694.

7. Possidente, B., and F.K. Stephan. 1988. Circadian period in mice: analysis of genetic and maternal contributions to inbred strain differences. Behav. Gen. 18:109-117.

8. Ibuka, N., and H. Kawamura. 1975. Loss of circadian rhythm in sleepwakefulness cycle in the rat by suprachiasmatic nucleus lesions. Brain Res. 96: $76-81$.

9. Stephan, F.K., and I. Zucker. 1972. Circadian rhythms in drinking behavior and locomotor activity of rats are eliminated by hypothalamic lesions. Proc. Natl. Acad. Sci. USA. 69:1583-1586.

10. Vale, W., J. Spiess, C. Rivier, and J. Rivier. 1981. Characterization of a 41-residue ovine hypothalamic peptide that stimulates secretion of corticotropin and beta-endorphin. Science (Wash. DC). 213:1394-1397.

11. Carnes, M., S.J. Lent, B. Goodman, C. Mueller, J. Saydoff, and S. Erisman. 1990. Effects of immunoneutralization of corticotropin-releasing hormone on ultradian rhythms of plasma adrenocorticotropin. Endocrinology. 126:19041913.

12. Bagdy, G., G.P. Chrousos, and A.E. Calogero. 1991. Circadian patterns of plasma immunoreactive corticotropin, beta-endorphin, corticosterone and prolactin after immunoneutralization of corticotropin-releasing hormone. $\mathrm{Neu}$ roendocrinology. 53:573-578.

13. Kwak, S.P., M.I. Morano, E.A. Young, S.J. Watson, and H. Akil. 1993. Diurnal CRH mRNA rhythm in the hypothalamus: decreased expression in the evening is not dependent on endogenous glucocorticoids. Neuroendocrinology. 57:96-105.

14. Watts, A.G., and L.W. Swanson. 1989. Diurnal variations in the content of preprocorticotropin-releasing hormone messenger ribonucleic acids in the hypothalamic paraventricular nucleus of rats of both sexes as measured by in situ hybridization. Endocrinology. 125:1734-1738.

15. Schulte, H.M., G.P. Chrousos, P.W. Gold, J.D. Booth, E.H. Oldfield, G.B. Cutler, and D.L. Loriaux. 1985. Continuous administration of synthetic ovine corticotropin-releasing factor in man. Physiologic and pathophysiologic implications. J. Clin. Invest. 75:1781-1785.

16. Dijkstra, I., R. Binnekade, and F.J.H. Tilders. 1996. Diurnal variation in resting levels of corticosterone is not mediated by variation in adrenal responsiveness to adrenocorticotropin but involves splanchnic nerve integrity. Endocrinology. 137:540-547.

17. Kaneko, M., K. Kaneko, J. Shinsako, and M.F. Dallman. 1981. Adrenal sensitivity to adrenocorticotropin varies diurnally. Endocrinology. 109:70-75.

18. Cascio, C.S., J. Shinsako, and M.F. Dallman. 1987. The suprachiasmatic nuclei stimulate evening ACTH secretion in the rat. Brain Res. 423:173-178.

19. Akana, S., K.A. Scribner, M.J. Bradbury, A.M. Strack, C.-D. Walker, and M.F. Dallman. 1992. Feedback sensitivity of the rat hypothalamo-pituitaryadrenal axis and its capacity to adjust to exogenous corticosterone. Endocrinology. 131:585-594.

20. Van Cauter, E., E.T. Shapiro, H. Tillil, and K.S. Polonsky. 1992. Circadian modulation of glucose and insulin responses to meals: relationship to cortisol rhythm. Am. J. Physiol. 262:E467-E475.

21. Van Cauter, E., J.D. Blackman, D. Roland, J.P. Spire, S. Refetoff, and K.S. Polonsky. 1991. Modulation of glucose regulation and insulin secretion by circadian rhythmicity and sleep. J. Clin. Invest. 88:934-942.

22. Van Cauter, E., D. Desir, C. Decoster, F. Fery, and E.O. Balasse. 1989. Nocturnal decrease in glucose tolerance during constant glucose infusion. $J$. Clin. Endocrinol. Metabol. 69:604-611.

23. Tempel, D.L., T. Kim, and S.F. Leibowitz. 1993. The paraventricular nucleus is uniquely responsive to the feeding stimulatory effects of steroid hormones. Brain Res. 614:197-204.

24. Tempel, D.L., B.S. McEwen, and S.F. Leibowitz. 1992. Effects of adrenal steroid agonists on food intake and macronutrient selection. Physiol. Behav. 52:1161-1166.

25. Goodyer, I.M., J. Herbert, P.M. Altham, J. Pearson, S.M. Secher, and H.M. Shiers. 1996. Adrenal secretion during major depression in 8- to 16-yearolds, I. Altered diurnal rhythms in salivary cortisol and dehydroepiandrosterone (DHEA) at presentation. Psychological Med. 26:245-256.

26. Trestman, R.L., R. Yehuda, E. Coccaro, T. Horvath, P. Knott, S. Gabriel, and L.J. Siever. 1995. Diurnal neuroendocrine and autonomic function in acute and remitted depressed male patients. Biol. Psychiatry. 37:448-456.

27. Nemeroff, C.B., E. Widerlov, G. Bissette, H. Walleus, I. Karlsson, K. Eklund, C.D. Kilts, P.T. Loosen, and W. Vale. 1984. Elevated concentrations of CSF corticotropin-releasing factor-like immunoreactivity in depressed patients. Science (Wash. DC). 226:1342-1344.

28. Thase, M.E., S. Dube, K. Bowler, R.H. Howland, J.E. Myers, E. Friedman, and D.B. Jarrett. 1996. Hypothalamic-pituitary-adrenocortical activity and response to cognitive behavior therapy in unmedicated, hospitalized depressed patients. Am. J. Psych. 153:886-891.

29. Muglia, L.J., N.A. Jenkins, D.J. Gilbert, N.G. Copeland, and J.A. Majzoub. 1994. Expression of the mouse corticotropin-releasing hormone gene in 
vivo and targeted inactivation in embryonic stem cells. J. Clin. Invest. 93:20662072.

30. Muglia, L., L. Jacobson, P. Dikkes, and J.A. Majzoub. 1995. Corticotropin-releasing hormone deficiency reveals major fetal but not adult glucocorticoid need. Nature (Lond.). 373:427-432.

31. Jacobson, L., and J.A. Majzoub. 1997. Protein malnutrition increases plasma adrenocorticotropin and anterior pituitary proopiomelanocortin messenger ribonucleic acid in the rat. Endocrinology. 138:1048-1057.

32. Krieger, D.T., and H. Hauser. 1977. Suprachiasmatic nuclear lesions do not abolish food-shifted circadian adrenal and temperature rhythmicity. Science (Wash. DC). 197:398-399.

33. Gertz, B.J., L.N. Contreras, D.J. McComb, K. Kovacs, J.B. Tyrrell, and M.F. Dallman. 1987. Chronic administration of corticotropin-releasing factor increases pituitary corticotroph number. Endocrinology. 120:381-388.

34. Krieger, D.T. 1974. Food and water restriction shifts corticosterone, temperature, activity, and brain amine periodicity. Endocrinology. 95:11951201.

35. Keegan, C.E., J.P. Herman, I.J. Karolyi, K.S. O'Shea, S.A. Camper, and A.F. Seasholtz. 1994. Differential expression of corticotropin-releasing hormone in developing mouse embryos and adult brain. Endocrinology. 134:25472555.

36. Koob, G., M. Swerdlow, M. Seeligson, R. Sutton, J. Rivier, and W. Vale. 1984. Effects of alpha-flupenthixol and naloxone on CRF-induced locomotor activation. Neuroendocrinology. 39:459-464.

37. Dunn, A.J., and C.W. Berridge. 1990. Physiologic and behavioral responses to corticotropin-releasing factor administration: is CRF a mediator of anxiety or stress responses? Brain Res. Rev. 15:71-100.

38. Dallman, M.F., S.F. Akana, C.S. Cascio, D.N. Darlington, L. Jacobson, and N. Levin. 1987. Res. Prog. Horm. Res. 43:113-173.
39. Vaughn, J., C. Donaldson, J. Bittencourt, M.H. Perrin, K. Lewis, S. Sutton, R. Chan, A.V. Turnbull, D. Lovejoy, C. Rivier, J. Rivier, P.E. Sawchenko, and W. Vale. 1995. Urocortin, a mammalian neuropeptide related to fish urotensin I and to corticotropin-releasing factor. Nature (Lond.). 378:287-292.

40. Plat, L., M.M. Byrne, J. Sturis, K.S. Polonsky, J. Mockel, F. Fery, and E. Van Cauter. 1996. Effects of morning cortisol elevation on insulin secretion and glucose regulation in humans. Am. J. Physiol. 270:E36-E42.

41. Van Cauter, E., and F.W. Turek. 1994. Endocrine and other biological rhythms. In Endocrinology. L.J. Degroot, editor. W.B. Saunders, Philadelphia. 2487-2548.

42. Akana, S.F., C.S. Cascio, J.-Z. Du, N. Levin, and M.F. Dallman. 1986 Reset of feedback in the adrenocortical system: an apparent shift in the sensitivity of adrenocorticotropin to inhibition by corticosterone between morning and evening. Endocrinology. 119:2325-2332.

43. Keller-Wood, M.E., and M.F. Dallman. 1984. Corticosteroid inhibition of ACTH secretion. Endocrine Rev. 5:1-24.

44. Schurmeyer, T.H., G.C. Tsokos, P.C. Averginos, J.E. Balow, R. D'Agata, D.L. Loriaux, and G.P. Chrousos. 1985. Pituitary-adrenal responsiveness to corticotropin-releasing hormone in patients receiving chronic, alternate day glucocorticoid therapy. J. Clin. Endocrinol. Metabol. 61:22-27.

45. Takahashi, K., K. Hanada, K. Kobayashi, C. Hayafuji, S. Otani, and Y. Takahashi. 1979. Development of the circadian adrenocortical rhythm in rats: studied by determination of 24- or 48-hour patterns of blood corticosterone levels in individual pups. Endocrinology. 104:954-961.

46. Allen, C., and J.W. Kendall. 1967. Maturation of the circadian rhythm of plasma corticosterone in the rat. Endocrinology. 80:926-930.

47. Jones, K.L. 1990. The Cushing syndromes. Ped. Clin. N. Am. 37:1313- 